\title{
Maternal recto vaginal colonization in term and preterm deliveries
}

Mostafa Javanian¹, Zahra Akbarian $\operatorname{Rad}^{2}$, Mohsen Haghshenas Mojaveri², Azita Ghanbarpour Shiadeh³, Soheil Ebrahimpour $^{4}$

${ }^{1}$ MD., Infectious Diseases and Tropical Medicine, Faculty Member, Infectious Diseases and Tropical Medicine Research Center, Health Research Institute, Babol University of Medical Sciences, Babol, Iran

${ }^{2}$ MD., Neonatal-pediatric Disease, Faculty Member, Non-Communicable Pediatric Disease Research Center, Health Research Institute, Babol University of Medical Sciences, Babol, Iran

${ }^{3}$ MD., Obstetrics \& Gynecology, Infertility and Health Reproductive Research Center, Health Research Institute, Babol University of Medical Sciences, Babol, Iran

${ }^{4} \mathrm{PhD}$. of Clinical Sciences, Faculty member, Infectious Diseases and Tropical Medicine Research Center, Health Research Institute, Babol University of Medical Sciences, Babol, Iran

\section{Type of article: Original}

\begin{abstract}
Background and aim: Maternal recto-vaginal organisms are the main cause of early-onset sepsis in neonates. The aim of this study was to determine the most common organisms and compare maternal recto-vaginal colonization in term and preterm delivery.

Methods: This cross-sectional study was done from October 2014 through October 2016 among participants referred to Ayatollah Rouhani Hospital in Babol, Northern Iran. All pregnant women within gestational age (GA) $\geq 26$ weeks and labor pain were included in this study. By a cotton applicator, culture from the lower third of the vagina and another one from the rectum were taken and transported by Stuart media to the laboratory, and were cultured on main Medias within 24 hours. Then microorganisms in preterm and term delivery were compared together. Data were analyzed using SPSS 16. The variables were compared between two groups by chi-squared test, Fisher' $\mathrm{s}$ exact test and logistic regression. $\mathrm{P}<0.05$ was statistically considered significant.

Results: Among 511 mothers with successful culturing, 417 delivered at term and 94 fewer than 37 weeks. Staphylococcus epidermidis and Escherichia coli (E. coli) were the most abundant organisms. The frequency of E. coli in term and preterm delivery was $52.5 \%$ and $68.1 \%$ respectively $(\mathrm{p}=0.006$ ). Group B strep was more frequent in term delivery $(13.7 \%$ vs. $3.2 \%, \mathrm{p}=0.004)$.

Conclusion: Based on our findings, the frequency E. coli and other gram-negative bacteria were higher in preterm delivery groups which indicates the need to assess the efficacy of chemoprophylaxis in situations such as prolonged rupture of membrane, and preterm delivery.
\end{abstract}

Keywords: Sepsis; Recto-vaginal colonization; Preterm delivery

\section{Introduction}

Preterm delivery (gestational age $<37$ weeks) which leads to mortality and morbidity in the neonatal period is one of the important issues in obstetrics (1). The frequency of preterm delivery was an estimated $9.6 \%$ in 2005 by World Health Organization (WHO), while its risk was $18 \%$ in some areas in 2014 (2). Among the various risk factors that play an important role in preterm delivery, maternal genitourinary infection is a controllable and preventable one (3). Maternal rectovaginal organisms play an important role in the incidence of early-onset neonatal sepsis (4). The pattern of sepsis-causing organisms is different from one place to another and even only in one place during various

\section{Corresponding author:}

Dr. Zahra Akbarian Rad, Non-Communicable Pediatric Disease Research Center, Health Research Institute, Babol University of Medical Sciences, Babol, Iran.

Tel: +98.9111154874, Fax: +981132207918, Email: z.akbarian@mubabol.ac.ir

Received: July 05, 2017, Accepted: September 20, 2017, Published: October 2017

iThenticate screening: August 28, 2017, English editing: September 28, 2017, Quality control: October 03, 2017

This article has been reviewed / commented by three experts

(C) 2017 The Authors. This is an open access article under the terms of the Creative Commons Attribution-NonCommercialNoDerivs License, which permits use and distribution in any medium, provided the original work is properly cited, the use is non-commercial and no modifications or adaptations are made. 
periods. For example, the most common organism was group B streptococcus (GBS) in Western countries $(5,6)$. While they were E. coli, Klebsiella, and Acinetobacter in India and Enterobacter in Iran $(7,8)$. Prematurity and lowbirth weight among neonatal risk factors are very important in the incidence of early-onset neonatal sepsis because the protective function of the skin and epithelial surfaces are less than normal in premature infants (1). Bacteria causing early-onset neonatal sepsis have significantly changed over time. Regional differences affect types of bacteria causing sepsis. Few bacteria, including GBS and E. coli have been identified as the main pathogens in neonatal sepsis $(5,9)$. However, recent epidemiologic studies have suggested that the incidence of early-onset neonatal sepsis caused by GBS is reduced. These changes directly depend on the screening of mothers at 35-37 weeks of gestational age and prescribing the prophylactic antibiotics to mothers with the high-risk factor and positive culture. The use of prophylactic antibiotics reduces the risk of early-onset sepsis (EOS) caused by GBS during labor (6). Although, GBS is still considered one of the main pathogens causing sepsis (10). E. coli is the second most common pathogen and causes $24 \%$ EOS of which $81 \%$ is related to premature infants. E. coli is the most common pathogen and responsible for $33.4 \%$ of early-onset neonatal sepsis only in very low birth weight (VLBW) infants. This pathogen is commonly colonized in the vagina of the mother and it is possible for neonates to be infected with this organism in the peripartum period (5). Today, due to the increase of the preterm births (11) and increased survival rate of these infants and the great diversity of organisms in different regions, the aim of this study was to determine the rectovaginal colonization in pregnant women in the status of preterm deliveries for choosing logically the empirical antibiotic treatment in neonatal sepsis and providing more information for obstetricians to perform antibiotic therapy in situations such as prolonged rupture of membrane. This cross-sectional study was done during 2014 through Oct 2016. All pregnant women with the gestational age of $>26$ weeks, labor pain and no history of antibiotic therapy during one week before admission, hospitalized in Ayatollah Rouhani Hospital in Babol, Northern Iran, were entered into the study by receiving an informed consent form. Exclusion criteria were vaginal bleeding and antibiotic usage during the previous week. The recent study protocol was approved by the ethics committee of Babol University of Medical Sciences (ID: 9031015). On admission, one swab from the lower third of the vagina and another from the rectum (two samples) were taken using sterile cotton applicators for all mothers by a trained midwife and then sent to the laboratory in the Stuart transport medium within 24 hours. Then, the samples were cultured on main media such as: Eosin Methylene Blue (EMB), chocolate agar, MacConkey and blood ager. After growth of bacteria, the smear was prepared and gram staining was done to differentiate their shapes. Additional tests such as fermentation of sugar or enzymes and other tests of differentiation were carried out to observe gram-positive and negative cocci, coccobacillus or bacilli. Data were analyzed using SPSS 16. The variables were compared between two groups by chi-squared test, Fisher's exact test and logistic regression. $\mathrm{P}<0.05$ was statistically considered significant.

\section{Material and Methods}

This cross-sectional study was done during 2014 through Oct 2016. All pregnant women with the gestational age of $>26$ weeks, labor pain and no history of antibiotic therapy during one week before admission, hospitalized in Ayatollah Rouhani Hospital in Babol, Northern Iran, were entered into the study by receiving an informed consent form. Exclusion criteria were vaginal bleeding and antibiotic usage during the previous week. The recent study protocol was approved by the ethics committee of Babol University of Medical Sciences (ID: 9031015). On admission, one swab from the lower third of the vagina and another from the rectum (two samples) were taken using sterile cotton applicators for all mothers by a trained midwife and then sent to the laboratory in the Stuart transport medium within 24 hours. Then, the samples were cultured on main media such as: Eosin Methylene Blue (EMB), chocolate agar, MacConkey and blood ager. After growth of bacteria, the smear was prepared and gram staining was done to differentiate their shapes. Additional tests such as fermentation of sugar or enzymes and other tests of differentiation were carried out to observe gram-positive and negative cocci, coccobacillus or bacilli. Data were analyzed using SPSS 16. The variables were compared between two groups by chi-squared test, Fisher' $\mathrm{s}$ exact test and logistic regression. $\mathrm{P}<0.05$ was statistically considered significant.

\section{Results}

Sampling was successfully conducted in 511 singleton pregnant women in the current study. The participants were 16 to 43 years old. Their mean age was $25.78 \pm 5.55$ years and mean gestational age was $38.07 \pm 2.32$ weeks. In total, $369(72.2 \%)$ women delivered vaginally and $142(27.8 \%)$ by caesarean section. Among them, 417 (81.6\%) women had term ( $\geq 37$ weeks) and $94(18.4 \%)$ preterm ( $<37$ weeks) deliveries. The results of culture indicated 13 species of bacteria and fungi. The frequency distribution of bacteria in different cultures based on term and preterm delivery is illustrated in Table 1. Overall, Staphylococcus epidermidis and E. coli were the most common organisms. Among gram-negative bacteria, E. coli and Enterobacter Cloacae were more abundant than others. Frequency of E. coli in 
term and preterm was $52.5 \%$ (219 of 417 ) and $68.1 \%$ (64 of 96), respectively (CI: $0.39-0.86, \mathrm{RR}=0.58, \mathrm{p}=0.006$ ). Among gram-positive bacteria, Staphylococcus epidermidis and GBS were more abundant than others. Frequency of GBS in term and preterm was $13.7 \%$ (57 of 417) and 3.2\% (3 of 94), respectively (CI: 1.32-12.34, RR=4.03, $\mathrm{p}=0.004)$.

Table 1. Frequency of maternal rectovaginal microorganisms (by term \& preterm)

\begin{tabular}{|l|l|l|l|l|}
\hline Organism & Overall; $\mathrm{n}(\%)$ & Term $(\geq 37) ; \mathrm{n}(\%)$ & Preterm $(<37) ; \mathrm{n}(\%)$ & $\mathrm{p}$-value \\
\hline EnterobacterCloace & $190(37.2)$ & $150(36)$ & $40(42.6)$ & 0.233 \\
\hline Staphylococcus Epidermis & $285(55.8)$ & $231(55.4)$ & $54(57.4)$ & 0.718 \\
\hline E-coli & $283(55.4)$ & $219(52.5)$ & $64(68.1)$ & 0.006 \\
\hline GBS & $60(11.7)$ & $57(13.7)$ & $3(3.2)$ & 0.004 \\
\hline EnterobacterAerogen & $39(7.6)$ & $32(7.7)$ & $4(7.4)$ & 0.940 \\
\hline Candida Albicans & $50(9.8)$ & $43(10.3)$ & $7(7.4)$ & 0.398 \\
\hline Staphylococcus aureus & $19(3.7)$ & $18(4.3)$ & $1(1.1)$ & 0.132 \\
\hline Staphylococcus saprophyticus & $35(6.8)$ & $30(7.2)$ & $5(5.3)$ & 0.516 \\
\hline Other cons & $2(0.4)$ & $1(0.2)$ & $1(1.1)$ & 0.248 \\
\hline Pseudomonas & $3(0.6)$ & $1(0.2)$ & $2(2.1)$ & 0.030 \\
\hline Enterococci & $2(0.4)$ & $1(0.2)$ & $1(1.1)$ & 0.248 \\
\hline Klebciella & $3(0.6)$ & $2(0.5)$ & $1(1.1)$ & 0.503 \\
\hline Bacillus & $1(0.2)$ & $1(0.2)$ & $0(0)$ & 0.635 \\
\hline
\end{tabular}

\section{Discussion}

In the present study, Staphylococcus epidermises and E. coli were the most common organisms separated from rectovaginal cultures of pregnant women, while E. coli and after that Enterobacter Cloacae, were the most common isolated organisms among gram-negative bacteria so that the risk of E. coli separation was half in term delivery than preterm. Among gram-positive organisms, Staphylococcus epidermises as the normal flora of mucosa and then GBS were respectively obtained from the cultures. Isolated GBS was almost four times in term than preterm delivery. Several types of research have acknowledged that although intrapartum antibiotic prophylaxis (IAP) can reduce EOS caused by GBS to 3-4\% per 1000 live births, E. coli is already the most abundant pathogen in EOS among VLBW neonates (12). It should be noted, despite the fact there is increased gentamicin and ampicillin resistance in E. coli isolates, this therapy is adequate for empirical coverage of EOS $(13,14)$. Stoll et al. conducted a study on EOS in neonates and concluded that $73 \%$ of isolated GBS was in term babies whereas $81 \%$ of isolated E. coli was in preterm and VLBW infants, and the highest mortality rate belonged to E. coli infection (9). In research on insolated organism of mothers with preterm deliveries by other researches, ureaplasma urealyticum, mycoplasma hominies, Gardnerella, chlamydia, Tricomonas and GBS were more common $(11,15,16)$. These different results, compared to the current study, may be due to the regional differences and socioeconomic status. Different studies in Iran on the causes of EOS suggested that Enterobacter was the most common organism in term and preterm neonates $(8,17)$. Since the bacterial cause of EOS is transmitted by mothers, it seems that gram-negative bacteria are the most common pathogens, as in the present study, Enterobacter was the second most common gram-negative organism. Nili et al. evaluated EOS in newborns and demonstrated that aerobic and anaerobic organisms occurred in $75 \%$ and $25 \%$ of EOS, respectively (14). A large number of sepsis cases are caused by coagulase-negative staphylococci (CONS) and Staphylococcus aureus; also, other gram-positive within 20\% and gram-negative organisms less than before can cause sepsis $(18,19)$, while these two organisms had a lower frequency in term and preterm infants in the present study. Prematurity is one of the important risk factors for neonatal sepsis and maternal infection including UTI is the most common cause of preterm delivery (20-22). Paying attention to the infectious factors (especially gram-negative ones, mostly E. coli) in mothers can not only reduce the risk of preterm delivery but also prevent the incidence of early-onset neonatal sepsis. Therefore, investigation of other risk factors and especially other bacteria that we did not assess are recommended. Moreover, consideration of resistant to antibiotics for detecting effective drugs is very useful. The limitation of our study was positive history of systemic antibiotic administration in some pregnant women over a long period of time before admission into our study, which caused the cultures to be negative.

\section{Conclusions}

Based on our findings, the frequency of E. coli and other gram-negative bacteria were higher in preterm delivery groups which indicates the need to assess the efficacy of chemoprophylaxis in situations such as prolonged rupture 
of membrane, and preterm delivery. Also, it could help the better understanding of management of preterm delivery, and allow health care providers to minimize neonatal mortality.

\section{Acknowledgments:}

We thank the Clinical Research Development Unit of Rouhani Hospital for assistance in manuscript submission and their friendly support. Moreover, this work was supported by the Babol University of Medical Sciences (grant number: 928).

\section{Conflict of Interest:}

There is no conflict of interest to be declared.

\section{Authors' contributions:}

All authors contributed to this project and article equally. All authors read and approved the final manuscript.

\section{References:}

1) Iams JD. Prevention of preterm parturition. $N$ Engl J Med. 2014; 370(3): 254-61. doi: 10.1056/NEJMc1402822. PMID: 24806178.

2) Romero R, Dey SK, Fisher SJ. Preterm labor: one syndrome, many causes. Science. 2014; 345(6198): 760 5. doi: 10.1126/science.1251816. PMID: 25124429.

3) Murthy V, Kennea NL. Antenatal infection/inflammation and fetal tissue injury. Best Pract Res Clin Obstet Gynaecol. 2007; 21(3): 479-89. doi: 10.1016/j.bpobgyn.2007.01.010. PMID: 17363332.

4) Kliegman RM, Stanton B, St.Geme J, Schor NF, Behrman RF. Nelson text book of pediatrics. 19th ed. 2011: 2470 .

5) Simonsen KA, Anderson-Berry AL, Delair SF, Davies HD. Early-Onset Neonatal Sepsis. Clin Microbiol Rev. 2014; 27(1): 21-47. doi: 10.1128/CMR.00031-13. PMID: 24396135.

6) Scholl J, Nasioudis D, Boester A, Speleotes M, Grunebaum A, Witkin SS. Group B streptococcus alters properties of vaginal epithelial cells in pregnant women. Am J Obstet Gynecol. 2016; 214(3): 383. e1-5. doi: 10.1016/j.ajog.2015.12.053. PMID: 26928153.

7) Kerur BM, Bhat BV, Harish B, Habeebullah S, Kumar CU. Maternal genital bacteria and surface colonization in early neonatal sepsis. Indian J Pediatr. 2006; 73(1): 29-32. doi: 10.1007/BF02758256. PMID: 16444057.

8) Afsharpaiman S, Torkaman M, Saburi A, Farzaampur A, Amirsalari S, Kavehmanesh Z. Trends in incidence of neonatal sepsis and antibiotic susceptibility of causative agents in two neonatal intensive care units in Tehran, IR Iran. J clin neonatol. 2012; 1(3): 124. doi: 10.4103/2249-4847.101692. PMID: 24027707, PMCID: PMC3762027.

9) Stoll BJ, Hansen NI, Sánchez PJ, Faix RG, Poindexter BB, Van Meurs KP, et al. Early onset neonatal sepsis: the burden of group B Streptococcal and E. coli disease continues. Pediatrics. 2011; 127(5): 817-26. doi: $10.1542 /$ peds.2010-2217. PMID: 21518717.

10) Koenig JM, Keenan WJ. Group B. Streptococcus and early-onset sepsis in the era of maternal prophylaxis. Pediatr Clin North Am. 2009; 56(3): 689-708. doi: 10.1016/j.pcl.2009.04.003. PMID: 19501699.

11) Pararas M, Skevaki $C$, Kafetzis D. Preterm birth due to maternal infection: causative pathogens and modes of prevention. Eur J Clin Microbiol Infect Dis. 2006; 25(9): 562-9. doi: 10.1007/s10096-006-0190-3. PMID: 16953371.

12) Mukhopadhyay S, Puopolo KM. Risk assessment in neonatal early onsetsepsis. Seminars in perinatology. Elsevier; 2012.

13) Bizzarro MJ, Dembry LM, Baltimore RS, Gallagher PG. Changing patterns in neonatal Escherichia coli sepsis and ampicillin resistance in the era of intrapartum antibiotic prophylaxis. Pediatrics. 2008; 121(4): 689-96. doi: 10.1542/peds.2007-2171. PMID: 18381532.

14) Metsvaht T, Ilmoja ML, Parm Ü, Maipuu L, Merila M, Lutsar I. Comparison of ampicillin plus gentamicin vs. penicillin plus gentamicin in empiric treatment of neonates at risk of early onset sepsis. Acta Paediatr. 2010; 99(5): 665-72. doi: 10.1111/j.1651-2227.2010.01687.x. PMID: 20096030.

15) Tita AT, Andrews WW. Diagnosis and Management of Clinical Chorioamnionitis. Clin Perinatol. 2010; 37(2): 339-54. doi: 10.1016/j.clp.2010.02.003. PMID: 20569811.

16) Singh S, Swain S, Das L, Das PC, Sahoo S. Isolation and characterization of organisms in high vaginal swab culture in preterm pregnancy (28-37 week). Int J Reprod Contracept Obstet Gynecol . 2016; 5(11): 3853-8. doi: 10.18203/2320-1770.ijrcog20163853. 
17) Karambin M, Zarkesh M. Entrobacter, the Most Common Pathogen of Neonatal Septicemia in Rasht, Iran. Iran J Pediatr. 2011; 21(1): 83-7. PMID: 23056769.

18) Jean-Baptiste N, Benjamin DK, Cohen-Wolkowiez M, Fowler VG, Laughon M, Clark RH, et al. Coagulase-negative staphylococcal infections in the neonatal intensive care unit. Infect Control Hosp Epidemiol. 2011; 32(7): 679-86. doi: 10.1086/660361. PMID: 21666399.

19) Marchant EA, Boyce GK, Sadarangani M, Lavoie PM. Neonatal sepsis due to coagulase-negative staphylococci. Clin Dev Immunol. 2013; 2013: 586076. doi: 10.1155/2013/586076. PMID: 23762094, PMCID: PMC3674645.

20) Martius JA, Roos T, Gora B, Oehler MK, Schrod L, Papadopoulos T, et al. Risk factors associated with early-onset sepsis in premature infants. Eur J Obstet Gynecol Reprod Biol. 1999; 85(2): 151-8. PMID: 10584628.

21) Lin FY, Weisman LE, Troendle J, Adams K. Prematurity is the major risk factor for late-onset group B streptococcus disease. J infect dis. 2003: 15; 188(2): 267-71. doi: 10.1086/376457. PMID: 12854082.

22) Downey LC, Smith PB, Benjamin DK. Risk Factors and Prevention of Late Onset Sepsis in Premature Infants. Early hum dev. 2010; 86(Suppl 1): 7-12. doi: 10.1016/j.earlhumdev.2010.01.012. PMID: 20116186. 